\title{
Changing Pattern of Complementary and Alternative Medicine in Tikapur Nepal: A Hope for Future Health
}

\section{Ranabhat Chhabi ${ }^{1 *}$, YA Do ${ }^{2}$, DW Ahn ${ }^{3}$, KJ Lee ${ }^{3,4}$ and CB Kim ${ }^{1}$}

${ }^{1}$ Department of Preventive Medicine, Wonju College of Medicine Yonsei University, Wonju, Republic of Korea

${ }^{2}$ Management Support Team, Management Support Department, Korea International Cooperation Agency 825 Daewangpangyo-ro, Sujeong-go, Seongnam-si, Gyeonggido, 461-833 Republic of Korea

${ }^{3}$ Institute for Poverty Alleviation and International Development, Yonsei University Wonju, Republic of South Korea

${ }^{4}$ Department of Environmental Medical Biology, Wonju College of Medicine Yonsei University, Wonju, Republic of Korea

\begin{abstract}
Primitive Medicines; Ayurvedic Herbal and other treatment therapy are the oldest way of treatment in eastern philosophy and now it is classified Complementary and the Alternative Medicine (CAM). In Nepal they have been very famous since last century. There was high utilization in mid and far western region of Nepal in the past. So it is necessary to explore their use in that territory.
\end{abstract}

Objectives: The main objective of this study was to explore the available herbs product and their utilization as therapeutic.

Methodology: A cross sectional study was done within Kailali district in Nepal.The respondents were selected in systematic random sampling and the clusters were selected in PPS having $27 \%$ in household base. Pretested questionnaire were used for the study. Ethical Approved was taken from Nepal health research council and informed consent was taken from respondents. Epi data 3.1 version was used to entry the data and SPSS 20 was used for the data analysis. Chi Square test was used to show the association between different variable and CAM utilization.

Results: During the study 24 types of herbs were found in practice. About $1 / 4^{\text {th }}(23.7 \%)$ used the herbs as therapeutic use, Narayanpur used least proportion (10\%), and the people who had misconception of food used the herbs. More than $1 / 3^{\text {rd }}(37 \%)$ used those herbs for cough and respiratory symptoms. The person who had information about the cause of disease and the knowledge of preventive ways with the application of herbs were statistically significant $(p<0.0001)$.

Conclusion: The behavior of using CAM is very old practice and very effective of some illness even now. The utilization of therapy is done together with current allopathic treatment system and there is limited research of CAM utilization with comparative study. A comparative study should be necessary to find the implication of herbs with the modern allopathic system and economic aspects. If their application can be updated and used with research, it will have good result for the treatment.

Keywords: Ayurvedic; Herbal; Jadibuti; CAM; Palliative care

\section{Introduction}

Alternative medicine was defined late in the $20^{\text {th }}$ century as a type of medicine or treatment other than conventional medicine or health care [1]. Alternative medicine was named because of its use as an alternative to conventional medicine, which is practiced by medical doctors in western culture. Complementary and Alternative Medicine was introduced to the western world through immigrants from other countries.As an example of this, after the Vietnam war, many refugees sought a new life in America, incorporating the cultures and beliefs of that part of the world with those of America [2]. The origin of CAM is in Asia like, Japan Korea, India, Nepal, China etc. and there is still practice of Yoga, Ayurvedic Medicine, Herbal Medicine, Naturopathy, Acupuncture, Amchiand other local and cultural type of therapy. During the war period and world migration the practice of such therapy has been global [3]. As a therapy the almost source are the plants.

Complementary and alternative medicine (CAM) interventions are popular among consumers and are widely employed to treat diverse physical and mental health conditions [4]. The application of CAM use is estimated at 25\% among residents of the United Kingdom, [5] 50\% among German, French, and Australian population [5,6], and $42 \%$ to $69 \%$ among residents of the United States [6,7]. CAM is a major growth industry in Europe $[8,9]$. A summary of 26 surveys across 13 countries concluded that the prevalence of CAM use by cancer patients overall
$31.4 \%$ [10]. The results of a recent national survey show that nearly 38 percent of U.S. adults use CAM approaches to manage a range of physical and emotional health concerns, including pain, anxiety, and depression [11,12]. Recent studies in the United States [13] and abroad support the current use of alternative health care. For example, a 1994 survey of physicians from a wide array of medical specialties (in Washington State, New Mexico, and Israel) revealed that more than $60 \%$ recommended alternative therapies to their patients at least once in the preceding year, while $38 \%$ had done so in the previous month $[14,15]$. Herbal resources are other form of Ayurvedic wealth.

In 1999, the first national survey on CAM use among the general population in the Republic of Korea reported that $29 \%$ of the

*Corresponding author: Ranabhat Chhabi, Department of Preventive Medicine Wonju College of Medicine, Yonsei University, Wonju, Gangwon 220-701, Republic of Korea, E-mail: chhabir@gmail.com

Received Janaury 31, 2014; Accepted February 22, 2014; Published February 24, 2014

Citation: Chhabi R, Do YA, Ahn DW, Lee KJ, Kim CB (2014) Changing Pattern of Complementary and Alternative Medicine in Tikapur Nepal: A Hope for Future Health. Altern Integ Med 3: 153. doi:10.4172/2327-5162.1000153

Copyright: (C) 2014 Chhabi R, et al. This is an open-access article distributed under the terms of the Creative Commons Attribution License, which permits unrestricted use, distribution, and reproduction in any medium, provided the original author and source are credited. 
population, as determined by telephone interview, had used CAM within the preceding 12-month period [16]. In 2006, another surveys showed that the 3,000 subjects, 2,244 (74.8\%) reported using CAM in the previous 12-month period [17]. The application of the use of CAM was disease prevention, health promotion, anti-ageing beauty and weight reduction, stress management and stamina [17]. Similarly the application of CAM has been used to treat the cancer patients in Korea [18].

The application of use of the CAM with top 5 problems listed wereback problems (19.7\%); allergies (16.6\%); sprains/muscle strains (15.7\%); digestive problems (14.5\%); and lung problems, pneumonia, or respiratory infections (13\%) respectively [13]. The same study shows that the top 4 treatment categories were chiropractic (15.7\%); lifestyle diet (8.0\%); exercise/movement (7.2\%); and relaxation (6.9\%). The most frequently cited health problems treated with alternative therapies were chronic pain (37\%); anxiety, chronic fatigue syndrome, and "other health condition" (31\% each); sprains/muscle strains (26\%); addictive problems and arthritis (both 25\%); and headaches (24\%) [13]. Twothirds of women in this study followed conventional treatment for breast cancer with one or more CAM therapies, which, they believed, that they could prevent cancer recurrence, cosmetic use, tonic, reduce the fat and ageing and/or improve their quality of life [19]. The geographical structure and advanced bio-diversity has made it possible for the Himalayan country to grow different valuable medicinal plants. The Medicinal and Aromatic database of Nepal covers 1624 species of plants found in wild state or cultivated or naturalized or imported belonging to 938 genera and 218 families [20]. These are known to be used as medicine in Nepal.

The World Health Organization (WHO) estimates that 4 billion people, 80 percent of the world population, presently use herbal medicine for some aspect of primary health care [21]. Herbal medicine is a major component in all indigenous peoples' traditional medicine and a common element in Ayurvedic medicine. WHO notes that of 119 plant-derived pharmaceutical medicines, about $74 \%$ are used in modern medicine in ways that correlated directly with their traditional uses as plant medicines by native cultures [22]. Major pharmaceutical companies are currently conducting extensive research on plant materials gathered from the rain forests and other places for their potential medicinal value.

CAM utilization rate vary, depending on the particular geographic region and the ways in which "alternative/complementary medicine" is defined. Although some studies suggest that CAM use is greatest among those between the ages of 35 and 50 [23], a recent multivariate analysis found no significant effect of age on CAM utilization [24].

As described in Ayurveda, the Himalayan Jadibuti is used for healthy body and happy mind. These are used in different means such as toiletries and cosmetics; incense and aromas; health promoting agents, supplements and medicines; natural manures, pesticides; environmental cleaning and protection; food, food additives and drinks etc.

Traditional medicine, Ayurvedic medicine, herbal medicine, alternative medicine etc. are using as same term in most of the study. Some of the studies have been published in international journals too. Most of the researches are focused to explore the existing herbal product of Nepal but they are silent about the proportion of using herbal product in different sets of community as a therapy. It will be extra important that such plants can be linked with different set of demographic variables. On the other hand current practices of herbal products really alternative therapy with allopathic model are or not.

Such study is helpful to conduct further study in the area of different utilization practice with focusing confined area. Because previous studies have highlighted that limited people are using such treatment system, whereas herbal therapy activist clam that it is sufficient to cure many diseases and illness. Even most of the allopathic medicines are abstracted form herbal abstract. Finding the proportion of the CAM and is application is the first steps and then it is necessary to do research more specific and precise. The main focus of the study was to find out the current pattern of CAM and changing pattern of that use in other specific purpose. Globally, the importance of CAM in general illness because of the replacement of western medicine but as cosmetic, tonic, palliative care etc. their important is more famous.

\section{Methodology}

\section{Study design and sampling}

It was a cross sectional study conducted in Kailali District, the far western Regional of Nepal. Kailali district was selected purposively having one Municipality Tikapur and the surrounding 4 VDCs namely, Dhansingpur, Narayanpur, Durgauli and the Pathariya. Each VDC was stratified in 9 cluster and Municipality in 3 clusters on Population Propionate sampling (PPS) about 27\% which was 4204 House hold and the head of the family were the respondent of the research. Pre tested household questionnaire. The training was provided to the enumerators and the supervisor.

\section{Data analysis}

Data entry were completed to the Epi data 3.1 and analyzed by SPSS 20 version. The data were cleaned and verified by statistician for the data quality. The data were analyzed with univariate and bivariate analysis with Pearson chi square test in $95 \%$ confidence interval and probability 0.05 . The quality of data was maintained tool design, pilot study, and preparation of the guidelines for the supervisor, respondent and data entry personnel by parallel data entry with SPSS and Epi data software. After finalization of the draft peer review was done by the experts.

Another complementary study was done about the use of herbal product in different disease in 2 clusters having the 500 sample size randomly. For that purpose, pre tested questionnaires were used. For Ethical consideration, Nepal Health research council was followed, permission was taken from local VDC and Municipality, and there was valid agreement to conduct research from Ministry of Health and Population of Nepal. Informed consent was taken from household respondent.

\section{Result}

The availability of local herbs was asked to the respondents during the study. During that time they had replied about the use for their health problems since their practice in before the availability of modern allopathic medicines but most of the respondents (75\%) were not currently used. The study showed that the utilization of the CAM was $24 \%$ (10-29\%). Among the occupation, the service holders used the CAM $42 \%$ where unemployed household used only $20 \%$.

Most of the available herbs were used in gastro intestinal problems like diarrhoea, loose motion, stomachache, worms, gastritis etc. Similarly, easily available herbs like Basil (Tulashi), Amala, Pipala were used in respiratory problems especially in children. Few people $(\leq 15 \%)$ used herbs for fever and Diarrhoea but more than $1 / 3^{\text {rd }}(37 \%)$ 
People used those for in respiratory diseases. Even they have little bit knowledge for the therapeutic use by about half population $(46 \%)$ (Table 1).

Table 2 shows, $3 / 4^{\text {th }}(75 \%)$ people use the CAM with allopathic medicine, more than half (58\%) apply as a medicine at initial stage of the illness and more interestingly, more than half (51\%) belief that CAM is the good way to promote sexual health.

\section{Distribution and association of herbs application with different variables}

Statistical test was used to show the association between the variables.The following table 3 shows that, there is no any statistical significant ( $\mathrm{p}$ value $>0.05$ ) between the herbs use and with occupation, resident id status and the head of household during the research. Similarly, there is association between family type and knowledge about the cause of diseases and the preventive ways of disease with the application of herbs. Nowadays, people who have broad knowledge about the disease and illness are using the CAM $(\mathrm{p}=<0.001)$ (Tables $1-3)$.

\section{Discussion}

The application of primitive medicine is worldwide and it was the main treatment therapy before $18^{\text {th }}$ century where the allopathic medicine was alternative medicine. Now the situation is vice versa and the previous treatment practice is used as complementary and alternative medicine which includes several types of treatment practice [2]. Nepal is one of the great sources of herbal products and so many treatment practices [25]. The Kailali, a district of far western region was similar to other hilly district of Nepal. Of the 48 species from 46 genera and 40 families were displayed about the application of their in the study, indigenous uses of about $70 \%$ species resembled to the earlier ethno medicinal reports [26]. Such application coincides with this result. The prevalence of the local herbs to use for the therapeutic application is only $24.7 \%$ as a complementary use not as full treatment approach. Such research is not sufficient to prove their application it needs another clinical trial to prove exact application. There are $83 \%$ people live in rural area [27] and the modern allopathic system is not accessible to all grass root level. If facts prove about the therapeutic application of locally endemic disease, obviously these people could be benefited. Traditional herbal medicine renders primary health care needs of two thirds of the rural population of the Nepalese, represents a largely unexplored source for potential development of new drugs $[26,28,29]$.

Medicinal plants play vital roles in the Nepalese livelihood [30] and the use of medicinal plants is frequent in several Nepalese regions $[26,31]$. It is estimated that only $15-20 \%$ of the population of Nepal -living in and around urban areas-has access to modern medicinal facilities, whereas the rest depend on traditional medicines [32]. Nepal is a natural storehouse of medicinal plants $[33,34]$. Each year thousands of tons of raw material are exported, mostly to India, but also to Asia, Europe and America [35]. The government of Nepal aims to promote medicinal plant use and conservation programs for livelihood improvement and poverty alleviation through various policies. However, the contribution of this sector to the national economy is still nominal.

Protection and preservation, development and commercialization of indigenous knowledge and herbal resources have become an issue. Herbal resources have been over exploited as usual and indigenous

\begin{tabular}{|l|l|l|l|l|}
\hline Herbs Name & $\begin{array}{l}\text { Application as herbal tea and } \\
\text { other paste }\end{array}$ & Category & Frequency \\
\hline $\begin{array}{l}\text { Neem, Gurje Pomegranate, Guava leaf, Dhade, } \\
\text { Raktamul, Pepper mint (Pudina), Bark of Jamun tree, } \\
\text { Leaf of lemon tree, Bark of mango tree, Raw banana skin }\end{array}$ & $\begin{array}{l}\text { Diarrhoea and gastro intestinal } \\
\text { problems }\end{array}$ & Yes & 53 \\
\hline $\begin{array}{l}\text { Jatropha (Rithha), Dodder (Aakashbeli), Mugwort } \\
\text { (Titepati) Bark of papal tree Barmuda grass }\end{array}$ & Fever, jaundice, wounds, boils etc & Yes & 457 \\
\hline $\begin{array}{l}\text { Basil (Tulasi), Myrobalans (Amala), Long pepper (Pipala), } \\
\text { Batul pate }\end{array}$ & $\begin{array}{l}\text { Respiratory disease, fever, } \\
\text { common cold, poisoning etc }\end{array}$ & Yes & 75 \\
\hline No & 92 & 185 \\
\hline
\end{tabular}

Table 1: Utilization of herbs use for general illness $(N=500)$.

\begin{tabular}{|c|c|c|c|c|}
\hline Practice and attitude & Response & Category & Frequency & $\%$ \\
\hline \multirow{12}{*}{ Practice } & \multirow{3}{*}{ Practice of Herbs as treatment last year } & Frequently & 73 & 15 \\
\hline & & Seldom & 201 & 40 \\
\hline & & None & 226 & 45 \\
\hline & \multirow[t]{3}{*}{ Use of the herbal therapy in illness } & Single & 54 & 11 \\
\hline & & With allopathic medicine & 375 & 75 \\
\hline & & With traditional healers & 71 & 14 \\
\hline & \multirow[t]{3}{*}{ Time for herbs consumption } & Starting of illness & 280 & 56 \\
\hline & & During the illness & 140 & 28 \\
\hline & & As a tonic & 80 & 16 \\
\hline & \multirow[t]{3}{*}{ Specific use of CAM } & Chronic Disease and illness & 162 & 32 \\
\hline & & $\begin{array}{l}\text { Cancer and } \\
\text { Palliative care }\end{array}$ & 83 & 17 \\
\hline & & Sexual tonic & 255 & 51 \\
\hline \multirow[t]{4}{*}{ Attitude } & \multirow[t]{4}{*}{ Attitude of herbs towards therapeutic use } & Very useful & 47 & 9 \\
\hline & & Little bit & 231 & 46 \\
\hline & & Not useful & 8 & 2 \\
\hline & & Don't know & 214 & 43 \\
\hline
\end{tabular}

Table 2: Changing pattern of CAM $(n=500)$. 


\begin{tabular}{|c|c|c|c|c|}
\hline \multirow[t]{2}{*}{ Variables } & \multicolumn{3}{|c|}{ Crosstab Utilization of herbal plant } & \multirow{2}{*}{$\begin{array}{l}p \text { value } \\
(95 \% \mathrm{Cl})\end{array}$} \\
\hline & & No & Yes & \\
\hline \multirow{4}{*}{$\begin{array}{l}\text { Occupation having } \\
\text { agriculture }\end{array}$} & \multirow{2}{*}{ No } & 1699 & 584 & \multirow[t]{4}{*}{0.8} \\
\hline & & $74.4 \%$ & $25.6 \%$ & \\
\hline & \multirow{2}{*}{ Yes } & 77 & 25 & \\
\hline & & $75.5 \%$ & $24.5 \%$ & \\
\hline \multirow[t]{4}{*}{ Residence status } & \multirow{2}{*}{ Temporary } & 154 & 53 & \multirow[t]{4}{*}{0.74} \\
\hline & & $74.4 \%$ & $25.6 \%$ & \\
\hline & \multirow{2}{*}{ Permanent } & 3013 & 984 & \\
\hline & & $75.4 \%$ & $24.6 \%$ & \\
\hline \multirow[t]{4}{*}{ Head of household } & \multirow{2}{*}{ Female } & 885 & 260 & \multirow[t]{4}{*}{0.07} \\
\hline & & $77.3 \%$ & $22.7 \%$ & \\
\hline & \multirow{2}{*}{ Male } & 2282 & 777 & \\
\hline & & $74.6 \%$ & $25.4 \%$ & \\
\hline \multirow[t]{6}{*}{ Family type } & \multirow{2}{*}{ Single } & 1770 & 543 & \multirow[t]{6}{*}{0.004} \\
\hline & & $76.5 \%$ & $23.5 \%$ & \\
\hline & \multirow{2}{*}{ Extended } & 358 & 157 & \\
\hline & & $69.5 \%$ & $30.5 \%$ & \\
\hline & \multirow{2}{*}{ Joint } & 1039 & 337 & \\
\hline & & $75.5 \%$ & $24.5 \%$ & \\
\hline \multirow{4}{*}{$\begin{array}{l}\text { Known cause of } \\
\text { diseases }\end{array}$} & \multirow{2}{*}{ Poor knowledge } & 490 & 74 & \multirow[t]{4}{*}{$<0.001$} \\
\hline & & $86.9 \%$ & $13.1 \%$ & \\
\hline & \multirow{2}{*}{ Good knowledge } & 2677 & 963 & \\
\hline & & $73.5 \%$ & $26.5 \%$ & \\
\hline \multirow{4}{*}{$\begin{array}{l}\text { Know how to } \\
\text { prevent diseases }\end{array}$} & \multirow{2}{*}{ No knowledge } & 482 & 64 & \multirow[t]{4}{*}{$<0.001$} \\
\hline & & $88.3 \%$ & $11.7 \%$ & \\
\hline & \multirow{2}{*}{ Correct knowledge } & 2685 & 973 & \\
\hline & & $73.4 \%$ & $26.6 \%$ & \\
\hline
\end{tabular}

Table 3: Association between herbs application with different variables $(n=4204)$.

knowledge either humiliated or under threat of piracy. It has been estimated that four out of five medicinal plants utilized by human beings are collected currently from the wild. Since herbal resources are one of the most reliable sources of income for a majority of the people living in rural areas, competition for harvest begins before the right season.

Locals do not have scientific knowledge or technology and tools to harvest. Probability of regeneration, therefore, becomes lesser by the year and finally reaches extinction. There are two urgent steps required to check this: First, the local people who rely on such natural resources for their lives must be trained; second, encourage them to cultivate these herbs commercially. Research has found that due to change in socio-psychological factors and educational patterns, the present generations of traditional healers do not follow the old methods. This is a threat to indigenous knowledge

It has been estimated that around 119 pure chemical substances extracted from some 90 species of higher plants are used in medicines throughout the world. Over 21,000 plant names that have medicinal uses are reported by WHO (1992). In Nepal, more than 1,600 species of wild plants are used in traditional medicinal practice and majority of which await proper documentation [36]. Currently, people are using the allopathic medicine and herbs as a complementary even though the people who have wider knowledge are more attractive to use with scientific clarification. $(\mathrm{p} \leq 0.001)$

Previously, when there was no practice of allopathic medicine there was highly applicable of herbs in Nepal. Every people were compulsion to search and use in every day practice but when allopathic system interrupted in health system, the previous practice is near to disappear that the above findings shows. The young generation is indifferent with this system. Now there is going to be failure some of the chronic disease by allopathic system scientist have attention for the herbs application and exploration. For this new scientific research should be done more with comparative ways with the failure of the allopathic drugs.

\section{Limitation of the Study}

Previously the CAM was the leading approach of treatment in Nepal but now a day it is going to be disappeared. So the first step could be to find out the utilization ratio in the community. Later on the research should be focused on treatment efficacy, other aspects of herbal products and direct to the industrialization. There are very few articles in this area and it is necessary to find more and more in coming days. This article just explores the possibility of complementary and alternative medicine in the community and local area. In the survey the Information about the diseases was the perception of the respondents. It was not from any clinical diagnosis or checking their medical history or record. Therefore, the distribution of the disease may not reflect the true disease morbidity in the survey population.

\section{Acknowledgements}

This work was supported by the National Research Foundation of Korea Grant funded by the Korean Government (NRF-2013-S1A5B8-A01055336). It is because the publication was accomplished in 2013.

\section{References}

1. Zollman C, Vickers A (1999) What is complementary medicine? BMJ 319: 693696.

2. Levin J, Chatters LM, Taylor RJ (2005) Religion, health and medicine in African Americans: implications for physicians. J Natl Med Assoc 97: 237-249.

3. Alter JS (2005) Asian medicine and globalization.Univ of Pennsylvania Press.

4. Rafferty AP, McGee HB, Miller CE, Reyes M (2002) Prevalence of complementary and alternative medicine use: state-specific estimates from the 2001 Behavioral Risk Factor Surveillance System. Am J Public Health 92 $1598-600$.

5. Molassiotis A, Fernadez-Ortega P, Pud D, Ozden G, Scott JA, et al. (2005) Use of complementary and alternative medicine in cancer patients: a European survey. Ann Oncol 16: 655-663.

6. MacLennan AH, Myers SP, Taylor AW (2006) The continuing use of complementary and alternative medicine in South Australia: costs and beliefs in 2004. Med J Aust 184: 27-31

7. Astin JA, Pelletier KR, Marie A, Haskell WL (2000) Complementary and alternative medicine use among elderly persons: one-year analysis of a Blue Shield Medicare supplement. J Gerontol A Biol Sci Med Sci 55: M4-9.

8. Moenkhoff M, Baenziger O, Fischer J, Fanconi S (1999) Parental attitude towards alternative medicine in the paediatric intensive care unit. Eur J Pediatr 158: $12-17$.

9. Fisher P, Ward A (1994) Complementary medicine in Europe. BMJ 309: 107-111.

10. Ernst E, Cassileth BR (1998) The prevalence of complementary/alternative medicine in cancer: a systematic review. Cancer 83: 777-782.

11. Barnes PM, Bloom B, Nahin RL (2008) Complementary and alternative medicine use among adults and children: United States, 2007. US Department of Health and Human Services, Centers for Disease Control and Prevention, National Center for Health Statistics.

12. Unützer J, Klap R, Sturm R, Young AS, Marmon T, et al. (2000) Menta disorders and the use of alternative medicine: results from a national survey. Am J Psychiatry 157: 1851-1857.

13. Astin JA (1998) Why patients use alternative medicine: results of a national study. JAMA 279: 1548-1553.

14. Ernst E, Resch KL, White AR (1995) Complementary medicine. What physicians think of it: a meta-analysis. Arch Intern Med 155: 2405-2408.

15. MacLennan AH, Taylor AW, Wilson DH, Wilson D (2000)The prevalence of pelvic floor disorders and their relationship to gender, age, parity and mode of delivery. BJOG107: 1460-1470. 
Citation: Chhabi R, Do YA, Ahn DW, Lee KJ, Kim CB (2014) Changing Pattern of Complementary and Alternative Medicine in Tikapur Nepal: A Hope for Future Health. Altern Integ Med 3: 153. doi:10.4172/2327-5162.1000153

16. Lee SI, Khang YH, Lee MS, Koo HJ, Kang W, Hong CD (1992) Complementary and alternative medicine use in Korea: prevalence, pattern of use, and out-ofpocket expenditures. Korean J Prev Med 32: 546-555.

17. Ock SM, Choi JY, Cha YS, Lee J, Chun MS, et al. (2009) The use of complementary and alternative medicine in a general population in South Korea: results from a national survey in 2006. J Korean Med Sci 24: 1-6.

18. Kim MJ, Lee SD, Kim DR, Kong YH, Sohn WS, et al. (2004) Use of complementary and alternative medicine among Korean cancer patients. Korean J Intern Med 19: 250-256.

19. Henderson JW, Donatelle R (2004) Complementary and alternative medicine use by women after completion of allopathic treatment for breast cancer. Altern Ther Health Med 10: 52-57.

20. Biziou B (2006) The Joy of Ritual: Spiritual Recipies to Celebrate Milestones, Ease Transitions, and Make Every Day Sacred: Cosimo, Inc.

21. Wootton JC (2006) WHO global atlas of traditional, complementary and alternative medicine. Journal of Alternative \& Complementary Medicine12: 93-94.

22. Bodeker G, Ong CK (2005) World Health Organization Global Atlas of Traditional, Complementary, and Alternative Medicine: World Health Organization.

23. Kessler RC, Soukup J, Davis RB, Foster DF, Wilkey SA, et al. (2001) The use of complementary and alternative therapies to treat anxiety and depression in the United States. Am J Psychiatry 158: 289-294.

24. Healthcare $L$ (1998) The Landmark report on public perceptions of alternative care. Sacramento, Calif: Landmark Healthcare.

25. Singh MP, Malla SB, Rajbhandari SB, Manandhar A (1979) Medicinal plants of Nepal-retrospects and prospects. Economic Botany 33: 185-198.
26. Kunwar RM, Shrestha KP, Bussmann RW (2010) Traditional herbal medicine in far-west Nepal: a pharmacological appraisal. J Ethnobiol Ethnomed 6: 35

27. Statistics CBo (2011) National Population and Housing Census.

28. Uprety Y, Asselin H, Boon EK, Yadav S, Shrestha KK (2010) Indigenous use and bio-efficacy of medicinal plants in the Rasuwa District, Central Nepal. $J$ Ethnobiol Ethnomed 6: 3

29. Kunwar RM, Bussmann RW (2008) Ethnobotany in the Nepal Himalaya. J Ethnobiol Ethnomed 4: 24

30. Bhattarai KR, Ghimire M (2006) Commercially important medicinal and aromatic plants of $\mathrm{Nepal}$ and their distribution pattern and conservation measure along the elevation gradient of the Himalayas. Banko Janakari 16: 3-13.

31. Shrestha K, Tiwari N, Ghimire S (2000) Medicinal and aromatic plants database of Nepal (MAPDON). Proceedings of Nepal-Japan Joint Symposium on Conservation and Utilization of Himalayan Medicinal Plant Resources 53-74.

32. Sharma U, Malla K, Uprety R (2004) Conservation and management efforts of medicinal and aromatic plants in Nepal. Banko Janakari 14: 3-11.

33. Manandhar NP (2002) Plants and People of Nepal Timber Press. Oregon 192

34. Baral SR, Kurmi PP (2006) A compendium of medicinal plants in Nepal: Rachana Sharma Maijubahal, Kathmandu.

35. Popescu R, Kopp B (2013) The genus Rhododendron: an ethnopharmacological and toxicological review. J Ethnopharmacol 147: 42-62.

36. Uprety Y, Boon EK, PoudeIRC, Shrestha KK, Rajbhandary S, et al. (2010) Nontimber forest products in Bardiya district of nepal: indigenous use, trade and conservation. Journal of Human Ecology 30: 143-158. 